Article

\title{
Self-Compliant Bipolar Resistive Switching in SiN-Based Resistive Switching Memory
}

\author{
Sungjun Kim ${ }^{1}$, Yao-Feng Chang ${ }^{2}$, Min-Hwi Kim ${ }^{1}$, Tae-Hyeon Kim ${ }^{1}$, Yoon Kim ${ }^{3}$ and \\ Byung-Gook Park ${ }^{1, *}$ \\ 1 Department of Electrical and Computer Engineering, Inter-University Semiconductor Research \\ Center (ISRC), Seoul National University, Seoul 08826, Korea; thinlizzy@snu.ac.kr (S.K.); \\ minboysky@naver.com (M.-H.K.); taehyun4902@snu.ac.kr (T.-H.K.) \\ 2 Department of Electrical and Computer Engineering, The University of Texas at Austin, \\ Austin, TX 78758, USA; u9120009@gmail.com \\ 3 Department of Nanoenergy Engineering, Pusan National University, Busan 46241, Korea; \\ yoonkim@pusan.ac.kr \\ * Correspondence: bgpark@snu.ac.kr; Tel.: +82-2-880-7270 \\ Academic Editor: Horng-Tay Jeng \\ Received: 20 March 2017; Accepted: 25 April 2017; Published: 26 April 2017
}

\begin{abstract}
Here, we present evidence of self-compliant and self-rectifying bipolar resistive switching behavior in $\mathrm{Ni} / \mathrm{SiN}_{x} / \mathrm{n}^{+} \mathrm{Si}$ and $\mathrm{Ni} / \mathrm{SiN}_{x} / \mathrm{n}^{++} \mathrm{Si}$ resistive-switching random access memory devices. The $\mathrm{Ni} / \mathrm{SiN}_{x} / \mathrm{n}^{++} \mathrm{Si}$ device's $\mathrm{Si}$ bottom electrode had a higher dopant concentration (As ion $>10^{19} \mathrm{~cm}^{-3}$ ) than the $\mathrm{Ni} / \mathrm{SiN}_{x} / \mathrm{n}^{+}$Si device; both unipolar and bipolar resistive switching behaviors were observed for the higher dopant concentration device owing to a large current overshoot. Conversely, for the device with the lower dopant concentration (As ion $<10^{18} \mathrm{~cm}^{-3}$ ), self-rectification and self-compliance were achieved owing to the series resistance of the $\mathrm{Si}$ bottom electrode.
\end{abstract}

Keywords: memory; resistive switching; self-compliance; silicon nitride

\section{Introduction}

It is projected that, in the near future, NAND flash will be faced with scaling issues caused by cell-to-cell interference, hot carrier disturbance, and word-lines resistance [1]. Because overcoming these inherent physical limitations would cause the complexity of the fabrication process to increase, memory devices based on the new concept of resistive switching have been proposed [2-10]. Resistive-switching random access memory (RRAM), with its various redox-related chemical effects, is one of the most promising devices for future non-volatile memory applications because of its superior memory performance and scalability down to a few nanometers [11-15]. The cross-point array structure is the most effective structure for high-density memory applications [16-18]. Each memory cell is placed at the intersection points of the bit-lines and word-lines, which are perpendicular to each other. Unfortunately, the sneak current paths from the cells in a low-resistance state (LRS) can limit the array size [16-18]. Therefore, additional nonlinear elements, so-called selection devices, are required to suppress the leakage paths in a cross-point array. Many approaches for combining memory and nonlinear selection devices have been proposed [19-22]. Each approach has some disadvantages: an Si PN diode cannot provide a bidirectional selector function. Insulator-metal-transition (IMT) switching using $\mathrm{VO}_{x}$ is unsuitable in the sense that the selector performance is not maintained at high temperatures [23]. The switching mechanism in varistor-type and mixed-ionic-electronic-conduction (MIEC) selectors is not clear. When an Si bottom electrode (BE) is used in place of a conventional metal BE, nonlinear current-voltage (I-V) characteristics are achieved without additional selection 
devices $[24,25]$. The built-in selector function helps increase the nonlinearity in a cross-point array. RRAM devices with a metal-insulator-semiconductor (MIS) structure display unique resistive switching behaviors depending on the dopant type (i.e., n-type or p-type) and the concentration of impurities in the Si BE. Previously, we investigated SiN-based RRAM devices with diode-like self-rectification behavior in unipolar switching mode [26]. Even though unipolar switching has the advantage that all switching occurs in one direction, it also has the disadvantages of a relatively larger variation in the switching parameters and higher reset current, which are both major hurdles to RRAM commercialization. Having a RRAM device with self-compliance would simplify the driving circuit required to limit the current since the low-resistance state (LRS) can be controlled without external compliance. Moreover, self-compliance could reduce the reset current. In this study, we compared two devices with different doping concentrations in Si BE. The self-compliant and self-rectifying bipolar resistive switching in an $\mathrm{Ni} / \mathrm{SiN}_{x} / \mathrm{n}^{+}$-Si device is more favorable for the nonlinear low-current operation than $\mathrm{Ni} / \mathrm{SiN}_{x} / \mathrm{n}^{++}$-Si device for use in high-density memory applications.

\section{Experimental}

First, we used arsenic (As) ions as n-type dopant ions in the BE of the metal-insulator-semiconductor (MIS) structure. A 10-nm-thick $\mathrm{SiO}_{2}$ layer was grown by dry oxidation as the screen oxide before the ions were implanted at densities of $8 \times 10^{14} \mathrm{~cm}^{-2}$ and $2 \times 10^{13} \mathrm{~cm}^{-2}$ into single-crystal silicon to fabricate the $\mathrm{n}^{++} \mathrm{Si}$ and $\mathrm{n}^{+} \mathrm{Si}$ BEs, respectively. The lattice damage was repaired by annealing at $1000{ }^{\circ} \mathrm{C}$ to restore the single-crystal structure and activate the As ions. We deposited 5-nm-thick $\mathrm{SiN}_{x}$ films via low-pressure chemical vapor deposition (LPCVD) at $785^{\circ} \mathrm{C}$ after removal of the $\mathrm{SiO}_{2}$ layer. The process gas was a mixture of $\mathrm{SiH}_{2} \mathrm{Cl}_{2}$ (dichlorosilane) with a mass flow of $30 \mathrm{sccm}$ and $\mathrm{NH}_{3}(100 \mathrm{sccm})$. A 100-nm-thick Ni top electrode was deposited using a thermal evaporator. The patterning was performed through a shadow mask with a diameter of $100 \mu \mathrm{m}$. The electrical characterization for each device was conducted using the DC voltage sweep mode of a Keithley 4200-SCS semiconductor parameter analyzer. The voltage bias was applied to the Ni top electrode, while the Si BE was grounded. To analyze the $\mathrm{SiN}_{x}$ material deposited in our laboratory, X-ray photoelectron spectroscopy (XPS) analysis was performed using a Thermo VG ESCA Sigma Probe spectrometer operating at $15 \mathrm{kV}$ and $100 \mathrm{~W}$ with a monochromatic Al-K $\alpha$ radiation source. The calibration of the binding energy scale was set by fixing the $\mathrm{C} 1 \mathrm{~s}$ at $284.5 \mathrm{eV}$.

\section{Results and Discussion}

Figure 1a shows a schematic drawing of the $\mathrm{Ni} / \mathrm{SiN}_{x} / \mathrm{n}$ Si device. Figure $1 \mathrm{~b}$ shows the depth profiles of the $\mathrm{Ni} / \mathrm{SiN}_{x} / \mathrm{n}^{++} \mathrm{Si}$ and $\mathrm{Ni} / \mathrm{SiN}_{x} / \mathrm{n}^{+}$Si devices using secondary ion mass spectrometry. The effective dopant concentration in the BE was above $10^{19} \mathrm{~cm}^{-3}$ and below $10^{18} \mathrm{~cm}^{-3}$ for the $\mathrm{Ni} / \mathrm{SiN}_{x} / \mathrm{n}^{++} \mathrm{Si}$ and $\mathrm{Ni} / \mathrm{SiN}_{x} / \mathrm{n}^{+} \mathrm{Si}$ device, respectively. Figure $1 \mathrm{c}, \mathrm{d}$ show the XPS data of the $\mathrm{Si} 2 \mathrm{p}$ and $\mathrm{N}$ 1s spectra, respectively, for the $\mathrm{SiN}_{x}$ film deposited by LPCVD. The peak binding energies in the $\mathrm{SiN}_{x}$ film are centered at $101.2 \mathrm{eV}$ and $397.4 \mathrm{eV}$ for the Si $2 \mathrm{p}$ and N 1s peak, respectively [27]. The atomic concentration was calculated from the Si $2 \mathrm{p}$ and N 1s peaks; the N/Si ratio in the $\mathrm{SiN}_{x}$ was 0.89 .

Figure 2a shows the I-V characteristics of the unipolar resistive switching of the $\mathrm{Ni} / \mathrm{SiN}_{x} / \mathrm{n}^{++}$ $\mathrm{Si}$ device. After the electroforming step, reset switching occurs by sweeping from 0 to $4 \mathrm{~V}$, transitioning the device from the LRS to the high resistance state (HRS). The switching voltage of the set process that causes the device transition to the LRS is higher than that of the reset process for same polarity switching. For the formation process, a compliance current (CC) of $1 \mathrm{~mA}$ was used to limit the size of conducting paths. Figure $2 \mathrm{~b}$ shows the I-V characteristics of the bipolar resistive switching of the $\mathrm{Ni} / \mathrm{SiN}_{x} / \mathrm{n}^{++} \mathrm{Si}$ device. After the positive formation process, the reset and set processes occur for a negative and positive voltage sweep, respectively. The absolute set and reset voltages were no different between the unipolar and bipolar switching modes, indicating that $\mathrm{Ni} / \mathrm{SiN}_{x} / \mathrm{n}^{++} \mathrm{Si}$ devices have a 
non-polar resistive switching property. The conducting paths with LRS (caused by a large overshoot) will be disrupted by Joule heating for both unipolar and bipolar switching.

(a)
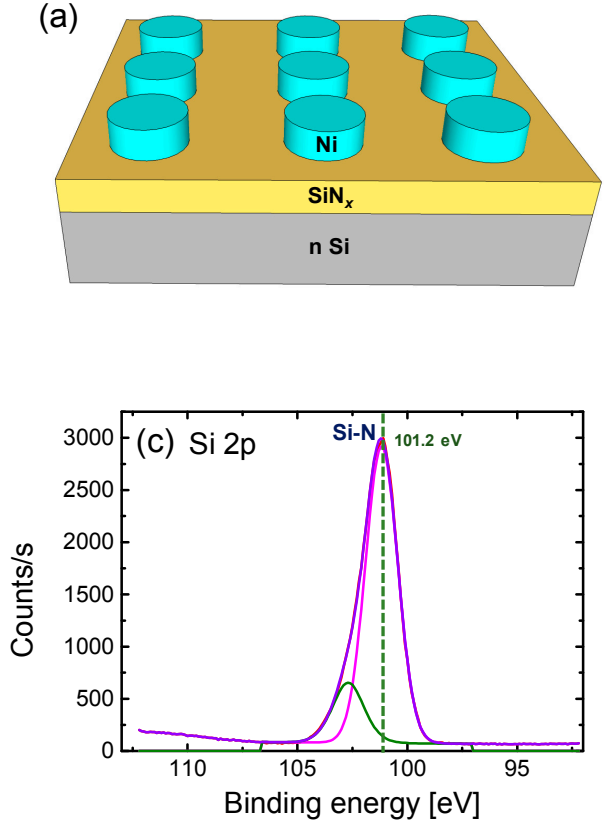


Figure 1. (a) Schematic drawing of $\mathrm{Ni} / \mathrm{SiN}_{x} / \mathrm{n}$-Si device; (b) Secondary ion mass spectrometry depth profile of the Si bottom electrode of the high and low dopant concentration sample; X-ray photoelectron spectroscopy (XPS) spectra of the $\mathrm{SiN}_{x}$ film deposited via low-pressure chemical vapor deposition (LPCVD): (c) Si 2p and (d) N 1s.
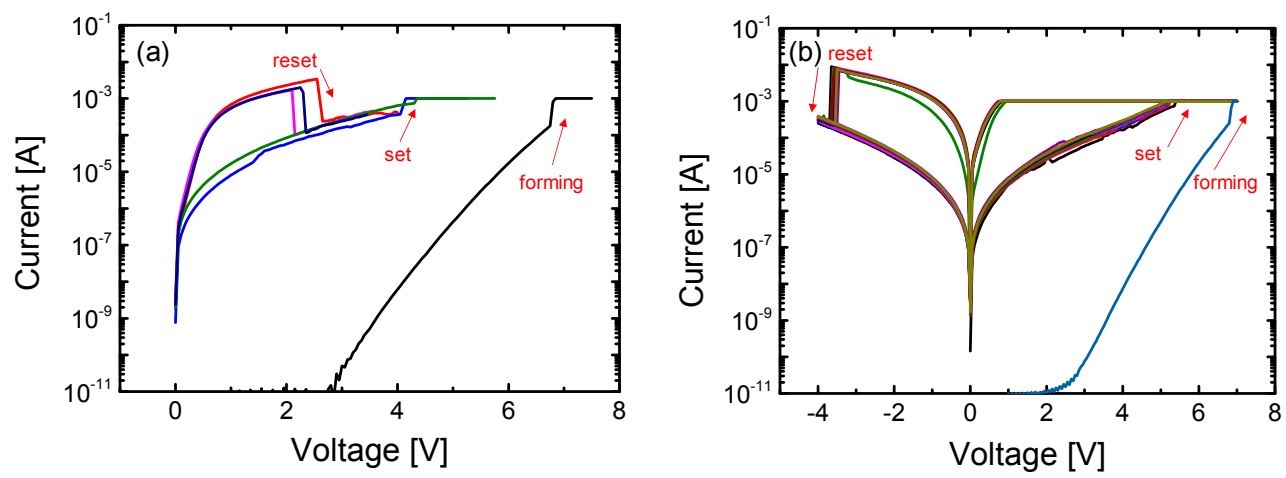

Figure 2. DC current-voltage (I-V) characteristics of the $\mathrm{Ni} / \mathrm{SiN}_{x} / \mathrm{n}^{++}$Si resistive-switching random access memory (RRAM) device for (a) unipolar switching and (b) bipolar switching.

The intrinsic switching in an SiN-based RRAM device can be induced by the generation and re-passivation of silicon dangling bonds. For the forming and set process, $\mathrm{Si}-\mathrm{H}$ bonds can be broken by accelerated electrons via thermal effects under high electric fields. Conversely, for the reset process, the resistance increases when hydrogen ions are connected with silicon dangling bonds [28].

Figure 3 shows the I-V characteristics for bipolar resistive switching of the $\mathrm{Ni} / \mathrm{SiN}_{x} / \mathrm{n}^{+}$Si device. A lower operating current than the $\mathrm{CC}$ was achieved since the reset switching in the bipolar switching for the $\mathrm{Ni} / \mathrm{SiN}_{x} / \mathrm{n}^{+}$Si device is mostly driven by the electric field. Further evidence for the different reset switching mechanisms can also be observed in the form of different reset switching types. Gradual reset switching after abrupt switching, which involves multiple current drops, is observed for the $\mathrm{Ni} / \mathrm{SiN}_{x} / \mathrm{n}^{+}$Si device, while the $\mathrm{Ni} / \mathrm{SiN}_{x} / \mathrm{n}^{++}$Si device shows an abrupt and one-time current drop. 


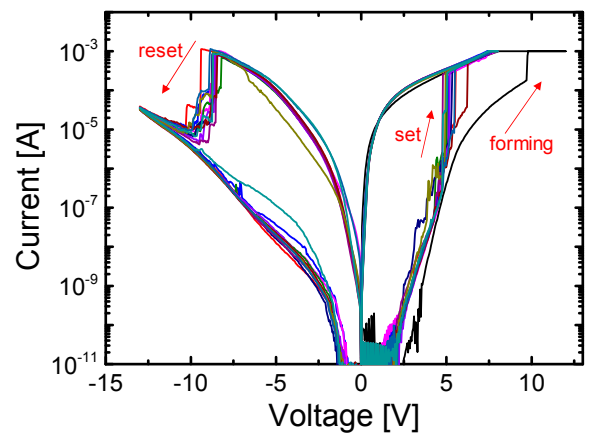

Figure 3. DC I-V bipolar resistive characteristics of the $\mathrm{Ni} / \mathrm{SiN}_{x} / \mathrm{n}^{+} \mathrm{Si}$ RRAM device.

Figure $4 \mathrm{a}, \mathrm{b}$ shows the distribution of the switching voltages, including the set and reset voltages, for $\mathrm{Ni} / \mathrm{SiN}_{x} / \mathrm{n}^{++} \mathrm{Si}$ and $\mathrm{Ni} / \mathrm{SiN}_{x} / \mathrm{n}^{+}$Si devices. The switching voltage is higher in the $\mathrm{Ni} / \mathrm{SiN}_{x} / \mathrm{n}^{+}$ Si device than in the $\mathrm{Ni} / \mathrm{SiN}_{x} / \mathrm{n}^{++}$Si device. This is attributed to the higher silicon surface resistance $\left(\mathrm{R}_{\mathrm{Si} \_ \text {SUR }}\right)$ in the $\mathrm{Ni} / \mathrm{SiN}_{x} / \mathrm{n}^{+}$Si device compared with the $\mathrm{Ni} / \mathrm{SiN}_{x} / \mathrm{n}^{++}$Si device; namely, $\mathrm{R}_{\mathrm{Si} \_S U R}$ in the $\mathrm{Ni} / \mathrm{SiN}_{x} / \mathrm{n}^{+}$Si device acts as a much larger voltage divider than that in the $\mathrm{Ni} / \mathrm{SiN} \mathrm{N}_{x} / \mathrm{n}^{++}$Si device during switching. It should be noted that the reset voltage $\left(\mathrm{V}_{\mathrm{RESET}}\right)$ of the $\mathrm{Ni} / \mathrm{SiN}_{x} / \mathrm{n}^{+}$Si device is much higher than that of the $\mathrm{Ni} / \mathrm{SiN}_{x} / \mathrm{n}^{++}$Si device. The resistance of the SiN film in the LRS is significantly reduced, since the resistance of the conducting paths ( $\left.\mathrm{R}_{\mathrm{SiN}_{-} \mathrm{CP}}\right)$ is dominant compared with the bulk resistance of the $\mathrm{SiN}$ film ( $\left.\mathrm{R}_{\mathrm{SiN} \_B U L K}\right)$ in the HRS as shown in Figure 4c. Hence, the active silicon surface resistance ( $\mathrm{R}_{\mathrm{Si} \_ \text {SUR }}$ ) plays an important role in reset switching compared with set switching.

Figure 5 shows the I-V characteristics of set switching for both devices. Unlike the $\mathrm{Ni} / \mathrm{SiN}_{x} / \mathrm{n}^{++}$ Si device, the $\mathrm{Ni} / \mathrm{SiN}_{x} / \mathrm{n}^{+}$Si device shows self-compliance behavior under $1 \mathrm{~mA}$ during the set process. The resistance value slowly decreases with increasing voltage after the abrupt set switching. This autonomous current limitation functionality is caused by the active silicon surface acting as a non-breakable series resistor.
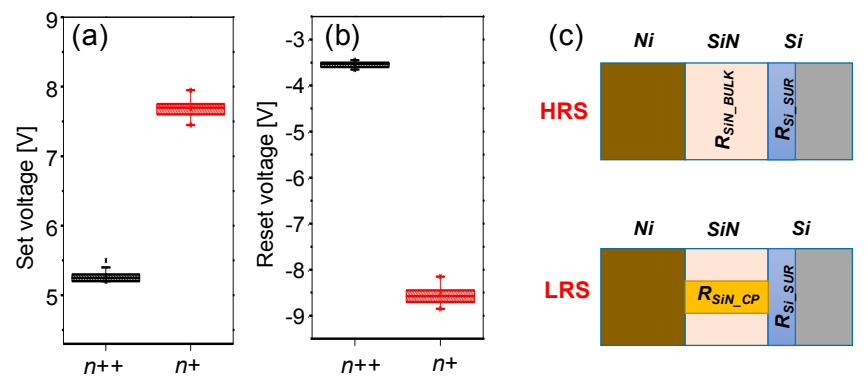

Figure 4. Statistical distribution of (a) the set voltage and (b) the reset voltage; (c) Schematics illustrating the $\mathrm{Ni} / \mathrm{SiN} / \mathrm{Si}$ structure in the high resistance state (HRS) and the low resistance state (LRS).

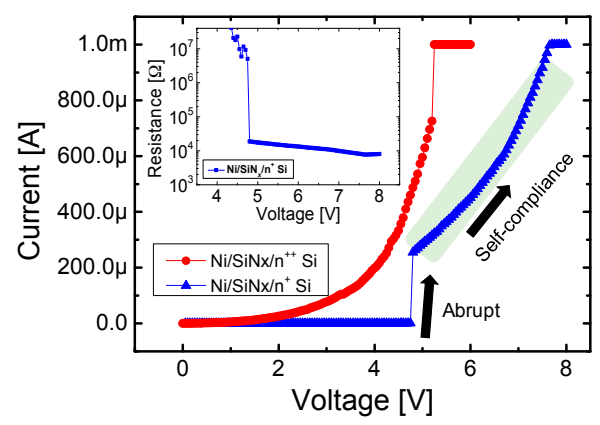

Figure 5. Self-compliance behavior in the LRS for the $\mathrm{Ni} / \mathrm{SiN}_{x} / \mathrm{n}^{++} \mathrm{Si}$ and $\mathrm{Ni} / \mathrm{SiN}_{x} / \mathrm{n}^{+} \mathrm{Si}$ devices. 
It should be noted that both the LRS current (at a read voltage, $\mathrm{V}_{\mathrm{READ}}$, of $0.2 \mathrm{~V}$ ) and the reset current $\left(\mathrm{I}_{\mathrm{RESET}}\right)$ of the $\mathrm{Ni} / \mathrm{SiN}_{x} / \mathrm{n}^{+}$Si device are lower than those of the $\mathrm{Ni} / \mathrm{SiN}_{x} / \mathrm{n}^{++}$Si device, as shown in Figure 6a,b, indicating that the self-compliance can suppress the current overshoot [29,30].
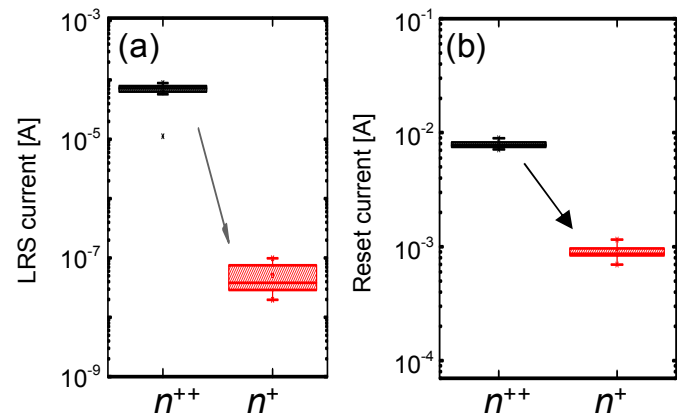

Figure 6. Statistical distribution of (a) the LRS current and (b) the reset current for $\mathrm{Ni} / \mathrm{SiN}_{x} / \mathrm{n}^{+} \mathrm{Si}$ device and $\mathrm{Ni} / \mathrm{SiN}_{x} / \mathrm{n}^{++}$Si devices.

To explore the devices' nonlinear performances, we further investigated the I-V characteristics in the LRS of both devices. The ratio of the current at $\mathrm{V}_{\mathrm{READ}}$ to that at $\frac{1}{2} \mathrm{~V}_{\mathrm{READ}}$ can be used to evaluate nonlinearity in partial voltage bias schemes such as the $\frac{1}{2} \mathrm{~V}_{\mathrm{READ}}$ scheme; this ratio is called the selectivity from here onwards. Figure $7 \mathrm{a}$, b shows the I-V curves of the $\mathrm{Ni} / \mathrm{SiN}_{x} / \mathrm{n}^{++} \mathrm{Si}$ and Ni$/ \mathrm{SiN}_{x} / \mathrm{n}^{+}$ Si device in the LRS, respectively, as well as the selectivity of each device. For the $\mathrm{Ni} / \mathrm{SiN}_{x} / \mathrm{n}^{++}$ Si device, the selectivity was observed to be above 2, indicating that the conducting paths are not perfectly ohmic; in comparison, for metal nitrides such as $\mathrm{AlN}$ and $\mathrm{NiN}$, which have strong metallic conducting filaments in the LRS, they show perfectly ohmic conduction [31,32]. This selectivity value of 2 is insufficient to suppress the sneak current paths in a cross-point array. Conversely, a selectivity of over 8 was obtained for the $\mathrm{Ni} / \mathrm{SiN}_{x} / \mathrm{n}^{+} \mathrm{Si}$ device. This is caused by the fact that very narrow conducting paths are more strongly dependent on two electric field-driven tunneling mechanisms, namely trap-assisted tunneling (TAT) and Fowler-Nordheim tunneling (FNT) [33-37].


Figure 7. Selectivity in the LRS for (a) the $\mathrm{Ni} / \mathrm{SiN}_{x} / \mathrm{n}^{++} \mathrm{Si}$ device and (b) the $\mathrm{Ni} / \mathrm{SiN}_{x} / \mathrm{n}^{+}$Si device.

Additionally, we calculated the forward-to-reverse ratio (F/ $\mathrm{R}$ ratio), since the reverse current in the LRS can significantly contribute to reducing the leakage current in a cross-point array [38]. Figure $8 \mathrm{a}, \mathrm{b}$ shows the I-V curves of the $\mathrm{Ni} / \mathrm{SiN}_{x} / \mathrm{n}^{++} \mathrm{Si}$ and $\mathrm{Ni} / \mathrm{SiN}_{x} / \mathrm{n}^{+}$Si devices in the LRS as well as showing the $\mathrm{F} / \mathrm{R}$ ratios. For the $\mathrm{Ni} / \mathrm{SiN}_{x} / \mathrm{n}^{++}$Si device, there are no differences between the forward current at positive voltages and the reverse current at negative voltages, which suggests that the carriers can move freely owing to the low barrier between SiN and Si BE. Conversely, a much higher $\mathrm{F} / \mathrm{R}$ ratio $\left(>376\right.$ at $\pm 0.5 \mathrm{~V}$ ) can be observed for the $\mathrm{Ni} / \mathrm{SiN}_{x} / \mathrm{n}^{+}$Si device. The $\mathrm{F} / \mathrm{R}$ ratio can be easily affected by the reverse current.

For the $\mathrm{Ni} / \mathrm{SiN}_{x} / \mathrm{n}^{++} \mathrm{Si}$ device, the reverse current region $(0$ to $-1 \mathrm{~V})$ of the LRS is dominated by ohmic conduction $(I \propto V)$, as can be seen in Figure 9a. Conversely, for the sample with the lower 
dopant concentration, the reverse current of the LRS is dominated by Schottky emission conducting transport in the reverse current region $(0$ to $-1 \mathrm{~V})$, where $\ln (\mathrm{I}) \propto \mathrm{V}^{1 / 2}[39]$.
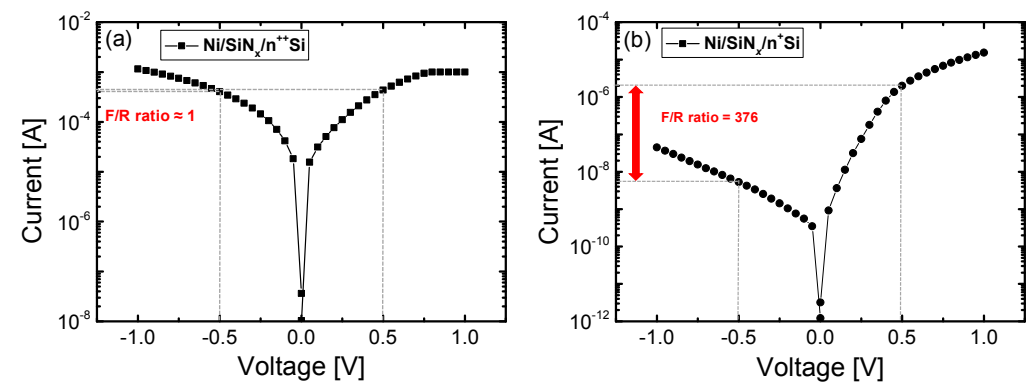

Figure 8. Forward-to-reverse ratio (F/R ratio) in the LRS for (a) the $\mathrm{Ni} / \mathrm{SiN}_{x} / \mathrm{n}^{++}$Si device and (b) the $\mathrm{Ni} / \mathrm{SiN}_{x} / \mathrm{n}^{+}$Si device.
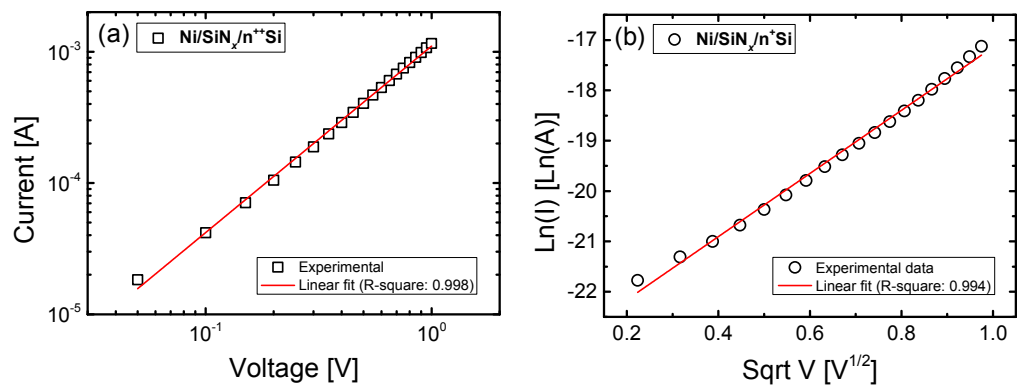

Figure 9. Experimental data and fitting results of the I-V curve in the LRS on (a) a log-log scale for $\mathrm{Ni} / \mathrm{SiN}_{x} / \mathrm{n}^{++} \mathrm{Si}$ and $(\mathbf{b})$ for $\ln (\mathrm{I})$ as a function of $\operatorname{sqrt}(\mathrm{V})$ for $\mathrm{Ni} / \mathrm{SiN}_{x} / \mathrm{n}^{+}$Si device.

To further enhance the nonlinearity as well as the selectivity and F/R ratio, we can control the conducting paths via the CC. For the $\mathrm{Ni} / \mathrm{SiN}_{x} / \mathrm{n}^{+}$Si device, the selectivity can be increased by decreasing the CC, as shown in Figure 10a, which suggests that this intrinsic nonlinear characteristic can be enhanced by narrowing the conducting paths. Figure $10 \mathrm{~b}$ shows the $\mathrm{F} / \mathrm{R}$ ratio as a function of the CC. The F/R ratio decreased when the CC was increased. The silicon nitride film can be modulated when the conducting paths are formed during the forming and set processes, causing the Schottky barrier to be lowered. Therefore, a low operating current switching is important in achieving a high nonlinearity of the LRS current. Further studies in the scaling effects on self-rectification and self-compliance are very important for ultra-high-density memory applications. For even smaller device sizes, the rectification behavior would be maintained and self-compliance would be observed at a lower current level owing to lower initial conducting defects in smaller cell sizes.
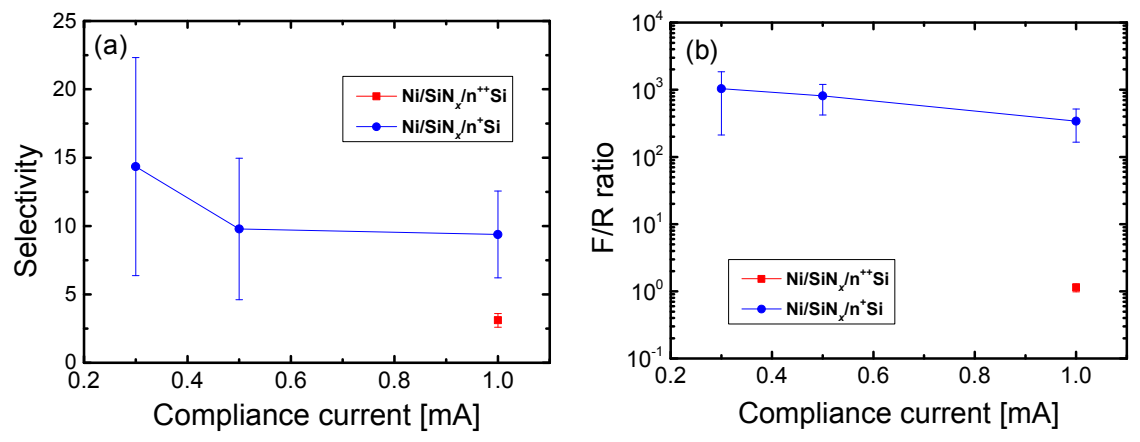

Figure 10. Nonlinearity as a function of the compliance current: (a) the selectivity and (b) the F/R ratio for $\mathrm{Ni} / \mathrm{SiN}_{x} / \mathrm{n}^{+}$Si device and $\mathrm{Ni} / \mathrm{SiN}_{x} / \mathrm{n}^{++}$Si devices. 


\section{Conclusions}

In summary, we investigated the self-compliant and self-rectifying bipolar resistive switching characteristics of $\mathrm{Ni} / \mathrm{SiN}_{x} / \mathrm{n}^{+}$Si devices. Different resistive switching behaviors were observed for the different dopant concentrations in silicon BE. The device with the lower dopant impurity concentration had a more nonlinear response and a low operating current in the LRS, while also displaying self-compliance set switching; this is in comparison with the device with the higher impurity concentration. All these results reveal that the BE doping-controlled $\mathrm{SiN}_{x}$ RRAM device in the MIS system would be suitable for high-density RRAM owing to its CMOS compatible structure and rectification and self-limiting properties.

Acknowledgments: This work was supported by the National Research Foundation of Korea (NRF) and funded by the Korean Ministry of Science, ICT \& Future Planning (MSIP) under grant No. 2015R1A2A1A01007307.

Author Contributions: Byung-Gook Park conceived and designed experiments; Min-Hwi Kim and Tae-Hyeon Kim helped perform the experiments; Sungjun Kim analyzed the data and wrote the manuscript with contributions from Yao-Feng Chang and Yoon Kim.

Conflicts of Interest: The authors declare no conflict of interest.

\section{References}

1. Kim, Y.; Kang, M.; Park, S.H.; Park, B.G. Three-Dimensional NAND Flash Memory Based on Single-Crystalline Channel Stacked Array. IEEE Electron. Device Lett. 2013, 34, 990-992. [CrossRef]

2. Goux, L.; Lisoni, J.G.; Jurczak, M.; Wouters, D.J.; Courtade, L.; Muller, C. Coexistence of the bipolar and unipolar resistive-switching modes in $\mathrm{NiO}$ cells made by thermal oxidation of Ni layers. J. Appl. Phys. 2010, 107, 024512. [CrossRef]

3. Xu, N.; Liu, L.F.; Sun, X.; Chen, C.; Wang, Y.; Han, D.D.; Liu, X.Y.; Han, R.Q.; Kang, J.F.; Yu, B. Bipolar switching behavior in $\mathrm{TiN} / \mathrm{ZnO} / \mathrm{Pt}$ resistive nonvolatile memory with fast switching and long retention. Semicond. Sci. Technol. 2008, 23, 075019. [CrossRef]

4. Chen, B.; Gao, B.; Sheng, S.W.; Liu, L.F.; Liu, X.Y.; Chen, Y.S.; Wang, Y.; Han, R.Q.; Yu, B.; Kang, J.F. A novel operation scheme for oxide-based resistive-switching memory devices to achieve controlled switching behaviors. IEEE Electron. Device Lett. 2011, 32, 282-284. [CrossRef]

5. Wong, H.S.P.; Lee, H.Y.; Yu, S.; Chen, Y.S.; Wu, Y.; Chen, P.S.; Lee, B.; Chen, F.T.; Tsai, M.J. Metal-Oxide RRAM. Proc. IEEE 2012, 100, 1951-1970. [CrossRef]

6. Linn, E.; Rosezin, R.; Kügeler, C.; Waser, R. Complementary resistive switches for passive nanocrossbar memories. Nat. Mater. 2010, 9, 403-406. [CrossRef] [PubMed]

7. Chang, Y.F.; Chen, P.Y.; Chen, Y.T.; Xue, F.; Wang, Y.; Zhou, F.; Fowler, B.; Lee, J.C. Study of polarity effect in $\mathrm{SiO}_{x}$-based resistive switching memory. Appl. Phys. Lett. 2012, 101, 052111. [CrossRef]

8. Chang, Y.F.; Chen, P.Y.; Fowler, B.; Chen, Y.T.; Xue, F.; Wang, Y.; Zhou, F.; Lee, J.C. Understanding the resistive switching characteristics and mechanism in active $\mathrm{SiO}_{x}$-based resistive switching memory. J. Appl. Phys. 2012, 112, 123702. [CrossRef]

9. Hsieh, C.C.; Roy, A.; Rai, A.; Chang, Y.F.; Banergee, S.K. Characteristics and mechanism study of cerium oxide based random access memories. Appl. Phys. Lett. 2015, 106, 173108. [CrossRef]

10. Celano, U.; Goux, L.; Degraeve, R.; Fantini, A.; Richard, O.; Bender, H.; Jurczak, M.; Vandervorst, W. Imaging the three-dimensional conductive channel in filamentary-based oxide resistive switching memory. Nano Lett. 2015, 15, 7970-7975. [CrossRef] [PubMed]

11. Chang, Y.F.; Chang, T.C.; Chang, C.Y. Investigation statistics of bipolar multilevel memristive mechanism and characterizations in a thin $\mathrm{FeO}_{x}$ transition layer of $\mathrm{TiN} / \mathrm{SiO}_{2} / \mathrm{FeO}_{x} / \mathrm{Fe}$ structure. J. Appl. Phys. 2011, 110, 053703. [CrossRef]

12. Feng, L.W.; Chang, C.Y.; Chang, Y.F.; Chang, T.C.; Wang, S.Y.; Chen, S.C.; Lin, C.C.; Chen, S.C.; Chiang, P.W. Improvement of resistance switching characteristics in a thin $\mathrm{FeO}_{x}$ transition layer of TiN $/ \mathrm{SiO}_{2} / \mathrm{FeO}_{x} / \mathrm{FePt}$ structure by rapid annealing. Appl. Phys. Lett. 2010, 96, 222108. [CrossRef]

13. Wang, Z.Q.; Li, X.H.; Xu, H.Y.; Wang, W.; Yu, H.; Zhang, X.T.; Liu, Y.X.; Liu, Y.C. Effects of compliance currents on the formation and rupture of conducting filaments in unipolar resistive switching of CoO film. J. Phys. D Appl. Phys. 2010, 43, 385105. [CrossRef] 
14. Long, S.; Lian, X.; Ye, T.; Cagli, C.; Perniola, L.; Miranda, E.; Liu, M.; Suñé, J. Cycle-to-cycle intrinsic reset satistics in $\mathrm{HfO}_{2}$-based unipolar RRAM devices. IEEE Electron. Device Lett. 2013, 34, 623-625. [CrossRef]

15. Lee, M.J.; Lee, C.B.; Lee, D.; Lee, S.R.; Chang, M.; Hur, J.H.; Kim, Y.B.; Kim, C.J.; Seo, D.H.; Seo, S.; et al. A fast, high-endurance and scalable non-volatile memory device made from asymmetric $\mathrm{Ta}_{2} \mathrm{O}_{5-\mathrm{X}} / \mathrm{TaO}_{2-\mathrm{X}}$ bilayer structures. Nat. Mater. 2011, 10, 625-630. [CrossRef] [PubMed]

16. Kim, S.; Kim, H.D.; Choi, S.J. Numerical study of read scheme in one-selector one-resistor crossbar array. Solid-State Electron. 2015, 114, 80-86. [CrossRef]

17. Zhou, J.; Kim, K.H.; Lu, W. Crossbar RRAM Arrays: Selector Device Requirements during Read Operation. IEEE Trans. Electron. Device Lett. 2014, 61, 1369-1367. [CrossRef]

18. Chang, K.C.; Chang, T.C.; Tsai, T.M.; Zhang, R.; Hung, Y.C.; Syu, Y.E.; Chang, Y.F.; Chen, M.C.; Chu, T.J.; Chen, H.L.; et al. Physical and chemical mechanisms in oxide-based resistance random access memory. Nanoscale Res. Lett. 2015, 10, 120. [CrossRef] [PubMed]

19. Chang, Y.F.; Fowler, B.; Chen, Y.C.; Zhou, F.; Pan, C.H.; Chang, T.C.; Lee, J.C.; Chang, T.C.; Chang, C.Y. Demonstration of Synaptic Behaviors and Resistive Switching Characterizations by Proton Exchange Reactions in Silicon Oxide. Sci. Rep. 2016, 6, 21268. [CrossRef] [PubMed]

20. Huang, J.J.; Tseng, Y.M.; Hsu, C.W.; Hou, T.H. Bipolar Nonlinear Ni/ $\mathrm{TiO}_{2} / \mathrm{Ni}$ Selector for $1 \mathrm{~S} 1 \mathrm{R}$ Crossbar Array Applications. IEEE Electron. Device Lett. 2011, 32, 1427-1429. [CrossRef]

21. Ji, L.; Chang, Y.F.; Fowler, B.; Chen, Y.C.; Tsai, T.M.; Chang, K.C.; Chen, M.C.; Chang, T.C.; Sze, S.M.; $\mathrm{Yu}$, E.T.; et al. Integrated One Diode-One Resistor Architecture in Nanopillar $\mathrm{SiO}_{x}$ Resistive Switching Memory by Nanosphere Lithography. Nano Lett. 2014, 14, 813-818. [CrossRef] [PubMed]

22. Jana, D.; Samanta, S.; Maikap, S.; Cheng, H.M. Evolution of complementary resistive switching characteristics using $\mathrm{IrO}_{x} / \mathrm{GdO}_{x} / \mathrm{Al}_{2} \mathrm{O}_{3} / \mathrm{TiN}$ structure. Appl. Phys. Lett. 2016, 108, 011605. [CrossRef]

23. Burr, G.W.; Shenoy, R.S.; Virwani, K.; Narayanan, P.; Padilla, A.; Kurdi, B.; Hwang, H. Access devices for 3D crosspoint memory. J. Vac. Sci. Technol. B 2014, 32, 040802. [CrossRef]

24. Kim, S.; Jung, S.; Kim, M.H.; Cho, S.; Park, B.G. Resistive switching characteristics of $\mathrm{Si}_{3} \mathrm{~N}_{4}$-based resistive-switching random-access memory cell with tunnel barrier for high density integration and low-power applications. Appl. Phys. Lett. 2015, 106, 212106. [CrossRef]

25. Wang, Z.; Kang, J.; Yu, Z.; Fang, Y.; Ling, Y.; Cai, Y.; Huang, R.; Wang, Y. Modulation of nonlinear resistive switching behavior of $\mathrm{TaO}_{x}$-based resistive device through interface engineering. Nanotechnology 2016, 28, 055204. [CrossRef] [PubMed]

26. Kim, S.; Cho, S.; Park, B.G. Fully Si compatible SiN resistive switching memory with large self-rectification ratio. AIP Adv. 2016, 6, 015021. [CrossRef]

27. Jiang, X.; Ma, Z.; Xu, J.; Chen, K.; Xu, L.; Li, W.; Huang, X.; Feng, D. a-SiN ${ }_{\mathrm{x}}$ : H-based ultra-low power resistive random access memory with tunable Si dangling bond conduction paths. Sci. Rep. 2015, 5, 15762. [CrossRef] [PubMed]

28. Yang, G.R.; Zhao, Y.P.; Hub, Y.Z.; Chow, T.P.; Gutmann, R.J. XPS and AFM study of chemical mechanical polishing of silicon nitride. Thin Solid Films 1998, 333, 219-223. [CrossRef]

29. Xu, Z.; Yu, L.; Wu, Y.; Dong, C.; Deng, N.; Xu, X.; Miao, J.; Jiang, Y. Low-energy Resistive Random Access Memory Devices with No Need for a Compliance Current. Sci. Rep. 2015, 5, 10409. [CrossRef] [PubMed]

30. Chang, Y.F.; Fowler, B.; Zhou, F.; Chen, Y.C.; Lee, J.C. Study of self-compliance behaviors and internal filament characteristics in intrinsic $\mathrm{SiO}_{x}$-based resistive switching memory. Appl. Phys. Lett. 2016, 108, 033504. [CrossRef]

31. Chen, C.; Yang, Y.C.; Zeng, F.; Pan, F. Bipolar resistive switching in Cu/AlN/Pt nonvolatile memory device. Appl. Phys. Lett. 2010, 97, 083502. [CrossRef]

32. Jeon, D.S.; Park, J.H.; Kim, M.J.; Kim, T.G. Low power NiN-based resistive switching memory device using Ti doping. Appl. Phys. Lett. 2016, 109, 183507. [CrossRef]

33. Kim, S.; Park, B.G. Nonlinear and multilevel resistive switching memory in $\mathrm{Ni} / \mathrm{Si}_{3} \mathrm{~N}_{4} / \mathrm{Al}_{2} \mathrm{O}_{3} / \mathrm{TiN}$ structures. Appl. Phys. Lett. 2016, 108, 212103. [CrossRef]

34. Kim, S.; Park, B.G. Improved multi-level capability in $\mathrm{Si}_{3} \mathrm{~N}_{4}$-based resistive switching memory using continuous gradual reset switching. J. Phys. D Appl. Phys. 2017, 50, 02LT01. [CrossRef]

35. Chang, Y.F.; Fowler, B.; Chen, Y.C.; Lee, J.C. Proton exchange reactions in $\mathrm{SiO}_{x}$-based resistive switching memory: Review and insights from impedance spectroscopy. Prog. Solid State Chem. 2016, 44, 75-85. [CrossRef] 
36. Chang, Y.F.; Fowler, B.; Zhou, F.; Wang, Y.; Chen, P.Y.; Xue, F.; Chen, Y.C.; Chen, Y.T.; Bringhurst, B.; Lee, J.C. Electroforming and resistive switching in silicon dioxide resistive memory devices. RSC Adv. 2015, 5, 21215-21236.

37. Chang, Y.F.; Fowler, B.; Chen, Y.C.; Chen, Y.T.; Wang, Y.; Xue, F.; Zhou, F.; Lee, J.C. Intrinsic SiO ${ }_{x}$-based unipolar resistive switching memory. I. Oxide stoichiometry effects on reversible switching and program window optimization. J. Appl. Phys. 2014, 116, 043708. [CrossRef]

38. Chen, C.; Pan, F.; Wang, Z.S.; Yang, J.; Zeng, F. Bipolar resistive switching with self-rectifying effects in $\mathrm{Al} / \mathrm{ZnO} / \mathrm{Si}$ structure. J. Appl. Phys. 2012, 111, 013702. [CrossRef]

39. Yan, P.; Li, Y.; Hui, Y.J.; Zhong, S.J.; Zhou, Y.X.; Xu, L.; Liu, N.; Qian, H.; Sun, H.J.; Miao, X.S. Conducting mechanisms of forming-free $\mathrm{TiW} / \mathrm{Cu}_{2} \mathrm{O} / \mathrm{Cu}$ memristive devices. Appl. Phys. Lett. 2015, 107, 083501. [CrossRef]

(c) 2017 by the authors. Licensee MDPI, Basel, Switzerland. This article is an open access article distributed under the terms and conditions of the Creative Commons Attribution (CC BY) license (http://creativecommons.org/licenses/by/4.0/). 